\title{
Nódulos pulmonares múltiples de reciente aparición en mujer diagnosticada de metástasis pleurales de un carcinoma de mama
}

\section{Sr. Director:}

Mujer de 50 años, sin AP de interés, fue diagnosticada en 1993 de un carcinoma ductal infiltrante de mama izquierda estadio clínico IIB (T2N1M0), moderadamente diferenciado, con receptores hormonales (estrógenos y progesterona) positivos y cerb-B2 positivo +3 . Se inició tratamiento quimioterápico neoadyuvante según el esquema 5-fluorouracilo, 4epirrubicina y ciclofosfamida (FEC) x 3 ciclos, seguido de una mastectomía radical y vaciamiento axilar. Tras la cirugía recibió tratamiento quimioterápico adyuvante (FEC X 3 ciclos) + radioterapia + hormonoterapia con tamoxifeno durante 5 años. En diciembre de 2002 se produjo progresión de la enfermedad con aparición de derrame pleural derecho. Se realizó toracoscopia diagnóstica con biopsia pleural. El informe anatomopatológico fue de infiltración por carcinoma de mama. Se pautó tratamiento quimioterápico con taxanos + trastuzumab (anticuerpo monoclonal anti cerb-B2) con remisión clínica completa de la enfermedad, continuando tratamiento hormonal de mantenimiento con un inhibidor de aromatasa. En su última revisión efectuada en mayo de 2005, la paciente se encontraba bien, y aportaba analítica, marcadores tumorales y TAC de tórax (Figura 1) dónde no se evidenciaban hallazgos significativos.

Un mes más tarde la paciente comenzó con clínica de tos acompañada de hemoptisis franca y fiebre de $38.5^{\circ} \mathrm{C}$. En una radiografía simple de tórax aparecieron nódulos pulmonares múltiples compatibles con metástasis pulmonares bilaterales como primera posibilidad. La paciente fue ingresada y se realizaron analíticas, sin alteraciones destacables excepto hemoglobina de $8.2 \mathrm{~g} / \mathrm{dl}$ (12-16). Los valores de los marcadores tumorales más utilizados en el segui-

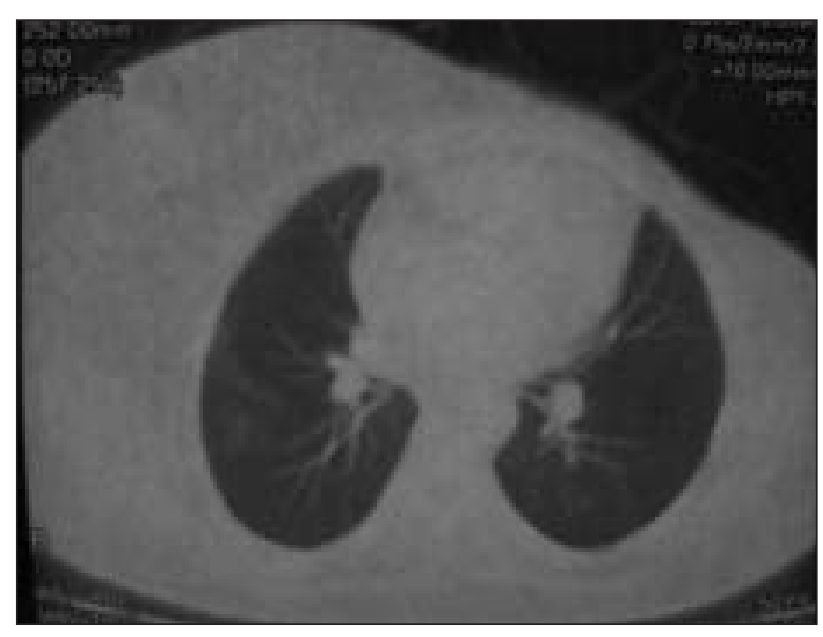

Figura 1.

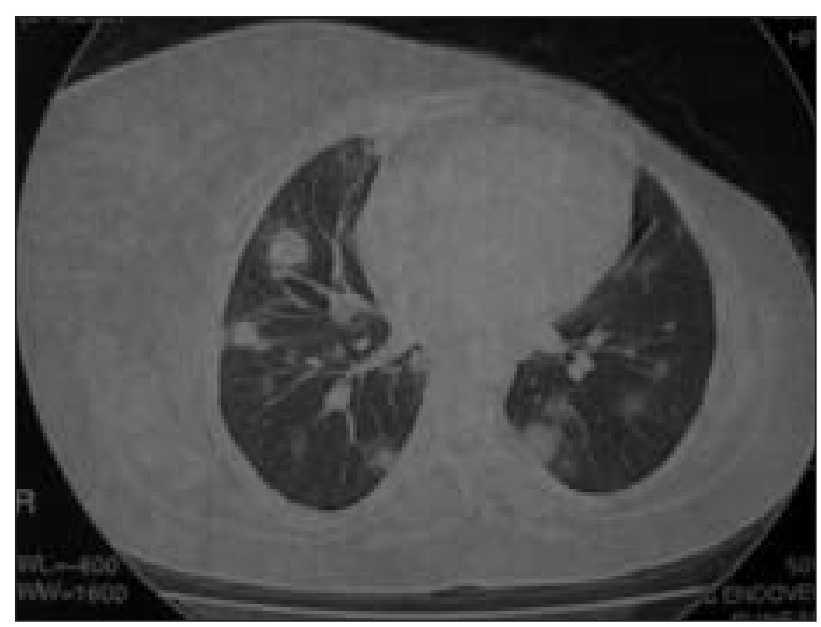

Figura 2.

miento del cáncer de mama (CEA, CA-15.3) se encontraban dentro de los rangos de la normalidad. Los resultados de los hemocultivos, antígeno de legionella en orina y serología de bacterias atípicas fueron negativos. Se realizó un test de gestación en 


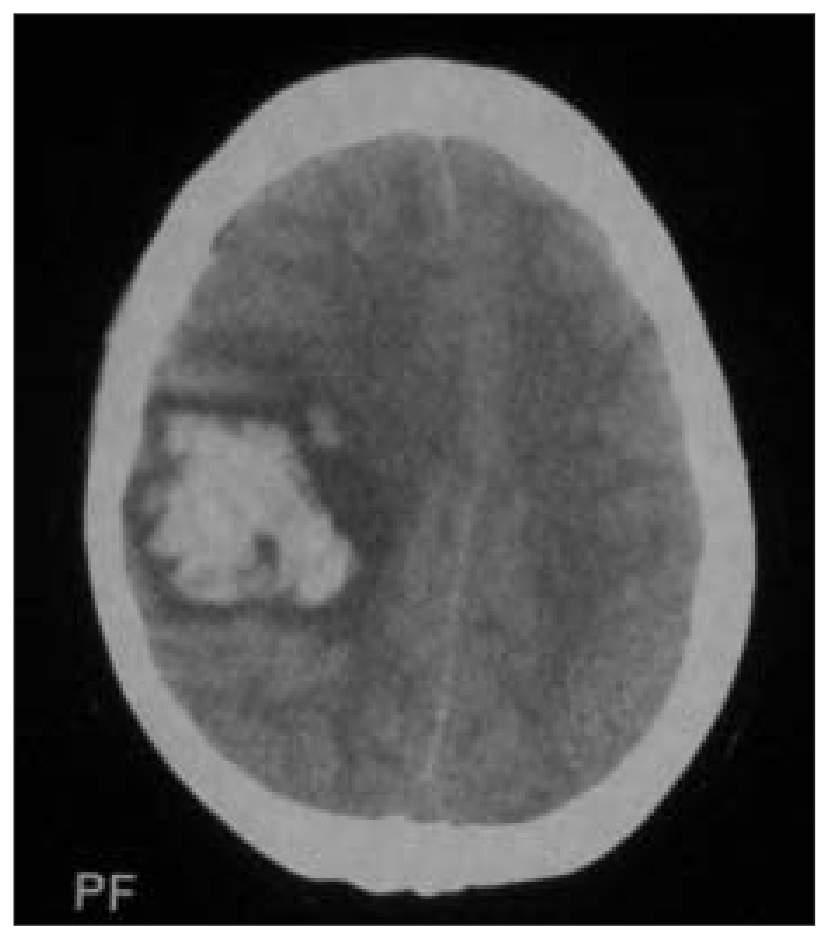

Figura 3.

orina que fue positivo, y el valor de la hormona (-gonadotrofina coriónica ( $\beta$-HCG) en sangre fue de $2424.97 \mathrm{mU} / \mathrm{ml}(0-5)$. Un TAC de tórax confirmó la existencia de imágenes nodulares múltiples en ambos campos pulmonares (Figura 2). Una biopsia transbronquial informó de la presencia de coriocarcinoma con áreas de necrosis y hemorragia. Cuatro días después del ingreso la paciente presentó un deterioro brusco del nivel de conciencia. Se realizó un TAC craneal dónde se apreció una hemorragia parenquimatosa extensa parieto-occipital derecha con importante edema y efecto masa, con otras lesiones corticales compatibles con metástasis (Figura 3). La paciente evolucionó desfavorablemente falleciendo en las 48 horas siguientes.

Diagnóstico: Metástasis pulmonares y cerebrales de coriocarcinoma

\section{Comentario}

El coriocarcinoma en su estado puro es una presentación extremadamente rara, y en su mayor parte coexiste con otros tumores germinales. Es un tumor con una enorme agresividad y rápido crecimiento. Como ocurrió en nuestra paciente, en el momento del diagnóstico suele haber metástasis viscerales múltiples, principalmente pulmonares y en el sistema nervioso central, con una gran tendencia al sangrado por su extraordinaria actividad angiogénica ${ }^{1,2}$.

El diagnóstico de coriocarcinoma requiere la presencia de citotrofoblasto y sincitiotrofoblasto ${ }^{1,2}$. La histología consiste en áreas o islotes centrales de citotrofoblasto, rodeado y separado por anillos de células multinucleadas de sincitiotrofoblasto, dando una apariencia bifásica o plexiforme. La hormona $\beta$-HCG, producida por el sincitiotrofoblasto, se encuentra elevada. Esta hormona polipeptídica es un marcador tumoral útil en el pronóstico de las pacientes, en el evaluación de la respuesta del tumor a la quimioterapia y en la detección de la recurrencia ${ }^{3}$.

Es necesario diferenciar el coriocarcinoma primario de ovario no gestacional y la enfermedad trofoblástica gestacional. La histología es similar en ambas patologías, pero el pronóstico es mucho peor en el tipo no gestacional ${ }^{2}$. Aunque en nuestra paciente no pudimos comprobar una lesión primaria en ovario debido a la tórpida evolución del cuadro, tampoco existía el antecedente de embarazo o aborto previo.

Existe otra entidad clínico-patológica descrita como es el carcinoma de mama con características de coriocarcinoma. Se define como un carcinoma ductal infiltrante de mama con evidencia histológica de hallazgos de coriocarcinoma y elevado niveles de $\beta-\mathrm{HCG}^{4,5}$. Suele ocurrir en mujeres peri o postmenopausica con carcinomas de mama pobremente diferenciados y receptores hormonales negativos. El curso evolutivo también es muy agresivo y las enfermas mueren en pocos meses debido a metástasis múltiples. Nuestra paciente fue diagnosticada de un carcinoma de mama en el año 1993, con posterior aparición de metástasis pleurales en el 2002. Había recibido tratamiento de quimioterapia en combinación con trastuzumab, y desde septiembre del 2003 se encontraba en remisión completa clínica y radiológica con terapia hormonal de mantenimiento, siendo su última revisión 1 mes antes del inicio del cuadro clínico. Se revisaron las biopsias del cáncer de mama y de la infiltración pleural metastática, no visualizándose componentes de coriocarcinoma. En la biopsia transbronquial no aparecieron elementos compatibles con carcinoma de mama. Por tanto, nuestro caso no parece compatible con este diagnóstico. 
Presentamos este caso debido a la inhabitual evolución radiológica de los nódulos pulmonares múltiples de reciente aparición en el contexto de una paciente con carcinoma de mama e infiltración pleural previa que se encontraba en remisión completa 1 mes antes. En tal situación creemos obligado considerar el diagnóstico diferencial de metástasis pulmonares de un carcinoma de mama con otras etiologías como enfermedades infecciosas o bien alguna patología oncológica de una extrema agresividad como se demostró con el posterior diagnóstico de coriocarcinoma.

\section{A. M. García Tapiador, A. Sánchez-Muñoz, E. Martínez Ortega, R. Dueñas García, A. L. Ortega Granados, A. Jaén Morago, P. Sánchez-Rovira Servicio de Oncología Médica Hospital Médico Quirúrgico Ciudad de Jaén Jaén (España)}

\section{Bibliografía}

1. Muggia F, Burke TW, Small W. Gestational trophoblastic diseases. En De Vita VT, et al (ed). Cancer, principles and practice of oncology. Philadelphia (USA): 7 . $^{\text {a ed. Lippincott }}$ Williams, 2005: 1360-1363.

2. Germá JR. Tumores germinales. Madrid (España): Nova Sidonia Oncología, 2000.

3. Aziz DC, Rittenhouse HJ and Ranken R. Use and interpretation of tests in oncology. Santa Mónica (USA): Specialty Laboratories Inc, 1991.

4. Resetkova E, Sahin A, Ayala AG and Sneige N. Breast carcinoma with choriocarcinomatous features. Ann Diagnostic Pathol 2004; 8(2):74-79.

5. Erhan Y, Özdemir N, Zekioglu O, Nart D and Ciris M. Breast carcinoma with choriocarcinomatous features: case report and review of the literature. The Breast Journal 2002; 8(4):244-248.

Correspondencia:

Dr. A. Sánchez Muñoz

C/ Poeta Francisco Coronado y Delicado, $4-3^{\circ} \mathrm{C}$ E-29011 Málaga

asmoncomed@yahoo.es 